\title{
Advancing image-guided implant dentistry innovation
}

Image Navigation has announced what it describes as the world's most advanced image-guided implant dentistry system, at the recent 2019 IDS in Cologne, Germany.

This new image-guided implant (IGI) system extends the use of СВCT scanners to include intra-surgical navigation and has real-time, speed of light, tracking with no on-screen lag.

It also has sub-millimetre accuracy and a robotic auto-stop for maximum safety where the drill motor stops automatically and instantly turns off the drill if it is placed outside of the planned surgical area.

Lawrence Obstfeld, Chief Executive Officer of Image Navigation, developer of the world's leading dental navigation technology, said: 'Our new system seamlessly integrates the advantages of freehand surgery, including unfettered vision of the surgical site, retention of the surgeon's tactile feel and the application of intra-surgical clinical judgment.'

The last few years have seen new opportunities open up in dentistry with significant growth in the dental implant market combined with technological improvements and cost reductions.

It is estimated that more than eight million dental implants were placed in patients across the world in 2018. In the UK, there were an estimated 260,000 implants in 2018 which is double the number from five years ago.

When using the IGI system, the dental surgeon views the tip of the drill and the pre-operative plan both superimposed onto a

\section{Dental dealer wins multi-million pound Ministry of Defence contract}

Dental Directory are the victors in the battle for a multi-million pound four-year contract to replace and install dental equipment across the Ministry of Defence's estate.

The contract will see Dental Directory become the sole supplier and installer of around 200 replacement A-dec dental chairs and almost 300 Acteon intraoral x-ray systems.

Its team of $60 \mathrm{UK}$-based engineers will install equipment in a variety of unusual locations on behalf of the Ministry of Defence, including warships and military bases.

Scott Selbie, Technical Services Director for Dental Directory said: 'We're delighted to have been awarded this prestigious contract.

'We have a proven track record when it comes to delivering projects on this scale and our close relationships with the Ministry of Defence's preferred brands, A-dec and Acteon, made our proposal extremely competitive.

'Many of our growing team of UK engineers have military experience and a working knowledge of the challenges these locations can bring to installation projects. It's an exciting contract and we're thrilled to be playing a part in it.'

The contract was won by Dental Directory following a competitive tender process run by Team Leidos, procurement partners for the Ministry of Defence and will run exclusively until 2023

For more information, visit www.dental-directory.co.uk.

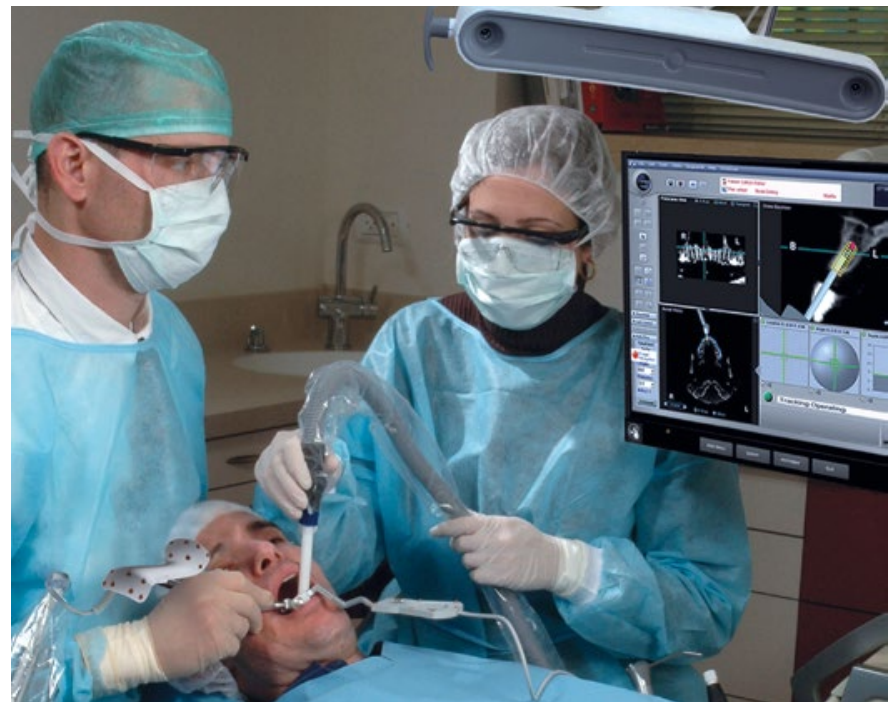

3-dimensional CT scan that displays the bone, adjacent teeth, nerve canal, roots and sinus area.

The IGI's on-screen display has a unique fluent tracking system with zero latency. It adds real-time navigated digital surgery to digital imaging, digital planning, and digital restorations.

Mr Obstfeld added: 'The surgeon is able to monitor the drilling path on-screen and make precise adjustments to ensure the most accurate dental implant placement during surgery.'

\section{Swift, convenient service}

As a dentist, practitioners need to find a dental laboratory that can offer them a wide range of services and will never let them down. Look no further than CosTech Dental Laboratory.

CosTech offers dentists a free personal pick-up and delivery service in and around north Kent and south London. The team is dedicated to ensuring that standards remain high across the board with stringent quality control checks in place.

Furthermore, an express turnaround service is available for those times when practitioners need a restoration swiftly, and the laboratory also offers freepost on all standard orders.

More information about CosTech Dental Laboratory is available by visiting www.costech.co.uk or calling 01474320076.

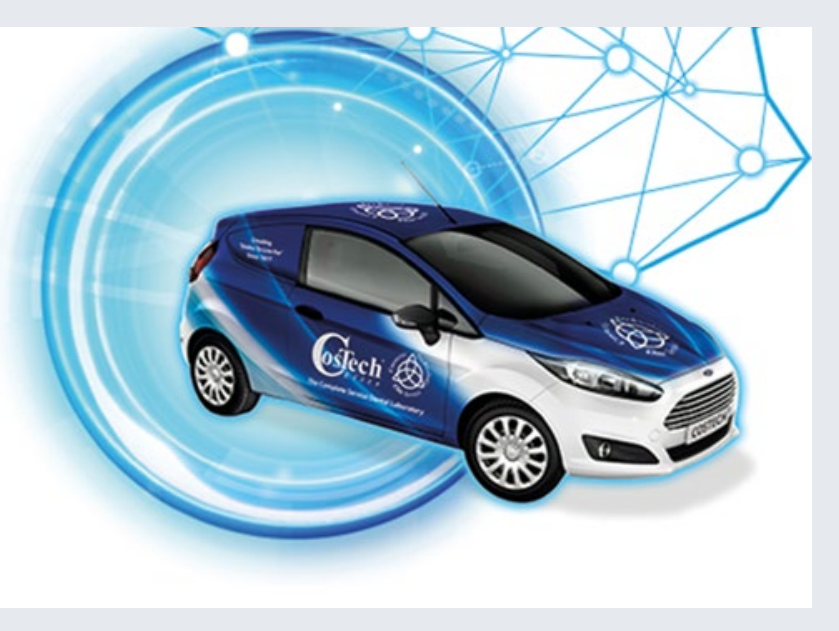

